\title{
Attraction toward a stranger as a function of direct and associated reinforcement'
}

\author{
WILLIAM B. GRIFFITT, DEPARTMENT OF PSYCHOLOGY, \\ UNIVERSITY OF HAWAII, Honolulu, Hawaii 96822
}

The experiment was designed to examine the effects of reinforcement directly attributable to a stranger and reinforcement associated in time with a stranger on the determination of attraction toward the individual. It was found that attraction varies positively $(p<.001)$ with the proportion of similar attitudes expressed by the stranger (direct reinforcement) and positively with the amount of reinforcement associated in time with the stranger $(p<.001)$. Attraction was found to be a linear function of weighted positive reinforcements.

Recent conceptualizations of the determinants of interpersonal attraction within the framework of S-R learning theory (Byrne, in press; Byrne \& Clore, 1967; Lott \& Lott, in press) have proven to be very fruitful both in terms of deriving testable hypotheses and accounting for a wide diversity of findings with respect to attraction phenomena. Within the general reinforcement framework, attraction responses are considered as one type of a more general class of evaluative responses. The basic proposition of a model to account for such evaluative responses presented by Byrne \& Clore (1967) is that the evaluation of a given stimulus is a positive linear function of the proportion of weighted positive reinforcements associated with the stimulus. Reinforcements are proposed to act as unconditioned stimuli (UCS) which give rise to implicit affective responses (UCR) mediating verbal evaluative responses of stimuli (CS) associated with the reinforcement. Similarly, Lott \& Lott (in press) presented four assumptions for their reinforcement approach to attraction: (1) persons represent discriminable stimuli, (2) reinforcement results in an overt or covert goal response ( $\mathrm{Rg}$ or $\mathrm{rg}$ ), (3) the goal response becomes conditioned to all discriminable stimuli present at the time of reinforcement, and (4) when such a goal response is conditioned to a person, that person in later situations will evoke $R_{g}$ or $r_{g}-\mathbf{s g}$. The association of another person (CS) with the implicit response is seen as leading to positive or negative attraction responses toward the person as a function of the reinforcement, incentive, habit, and drive parameters involved.

A consistent finding is that attraction toward a stranger is a positive linear function of the proportion of similar attitudes expressed by the stranger. Similar attitudes constitute positive reinforcements (Byrne, Young, \& Griffitt, 1966) and are considered reinforcements directly attributable to the stranger. The general reinforcement model also requires the positive relationship to hold for a situation in which the reinforcements are only associated with the stranger but not directly attributable to him. Recent findings by Byrne \& Clore (1967) suggest that this relationship holds. The present study was designed to further examine and clarify the relationship. Specifically, it was hypothesized that (a) attraction is a positive function of the proportion of similar attitudes (direct reinforcement) expressed by a stranger, and (b) a positive function of the amount of reinforcement associated in time (associated reinforcement) with a stranger.

Method. Students in an introductory psychology course at the University of Hawaii were administered a 12-item attitude scale. From this pool, 40 male and female Ss were selected for the experiment. Students in this course are

Table 1

Mean Attraction Responses Toward Stranger as a Function of Attitude Similarity and Bonus Credit Points

\begin{tabular}{rrr} 
& .25 & .75 \\
+4 & 8.60 & 10.90 \\
+0 & 6.70 & 9.60 \\
\hline
\end{tabular}

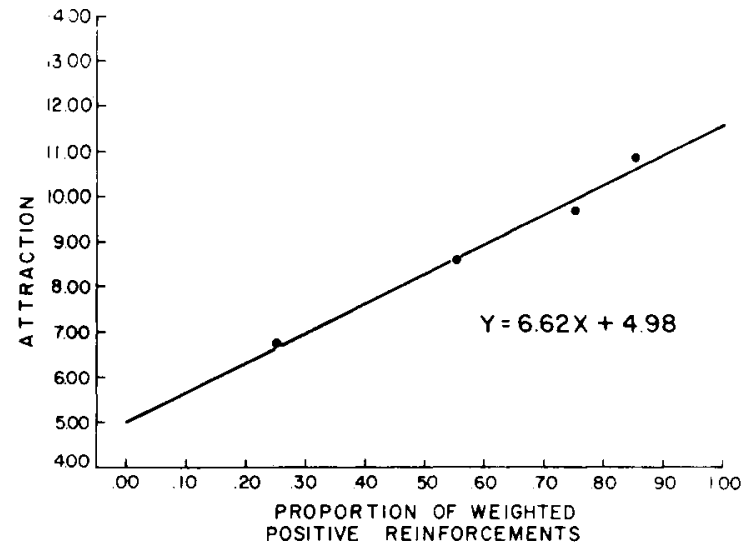

Fig. 1. Attraction toward stranger as a linear function of proportion of positive reinforcements based on weighted combinations of bonus points and attitude items.

given an opportunity to add points to their final course point total by participation in research projects for which one score point is awarded for each experiment participated in up to a maximum possible of five additional points. Several weeks after the initial testing, Ss were requested to evaluate an anonymous same-sex stranger on the basis of inspection of the stranger's attitude scale. In a 2 by 2 factorial design, two sources of reinforcement were created. The attitude scale responses attributed to the stranger were bogus ones prepared by $E$ to provide .25 or .75 agreement with $S$. This attitude similarity variable constitutes reinforcement directly attributable to the stranger. In addition, half of the $S s$ in the .25 and .75 similarity conditions were told that they would receive 4 bonus points of experimental credit for participating in the experiment in addition to the usual 1 credit point and thus obtain the maximum total of 5 points. The other half of the Ss in both similarity conditions were told that they would receive the usual 1 credit point. Thus, an additional source of reinforcement, not directly attributable to the mythical stranger but associated in time with him, was manipulated. The strangers were evaluated on the Interpersonal Judgment Scale, the last two items of which are summed to yield the measure of attraction.

Results. The means of the attraction responses are shown in Table 1. Analysis of variance indicated that both the similaritydissimilarity variable $(F=24.40, \mathrm{df}=1 / 36, \mathrm{p}<.001)$ and the bonus point variable $(\mathrm{F}=9.24, \mathrm{df}=1 / 36, \mathrm{p}<.001)$ yielded highly significant effects. The $F$ ratio for the interaction was less than one.

Discussion. As required by the reinforcement model, reinforcement associated with a stimulus person but not directly at tributable to him affects evaluation of the individual. Multiple stimulus determinants of attraction responses have previously been identified (Byrne \& Rhamey, 1965). The latter authors found that reinforcements concerning personal attributes of $S$ are of greater magnitude than attitude similarity reinforcements by a ratio of 3 to 1 . In the present investigation a weight of 2 was assigned to each bonus point unit and a weight of 1 to each attitude similarity unit, and attraction was plotted as a function of proportion of weighted positive reinforcements as shown in Fig. 1. A straight-line function was fitted to the data by the least squares method yielding the formula $Y=6.62 X+4.98$. It is apparent that at traction responses are influenced by reinforcement associated in time with a stranger in much the same way as by reinforcement directly attributable to him.

\section{REFERENCES}

BYRNE, D. Attitudes and attraction. In L. Berkowitz (Ed.), Advances in experimental social psychology. Vol. 4. New York: Academic Press, in press.

BYRNE, D., \& CLORE, G. L., Jr. A reinforcement model of evaluative responses. Unpublished manuscript, 1967. 
BYRNE, D., \& RHAMEY, R. Magnitude of positive and negative reinforcements as a determinant of attraction. J. Pers. soc. Psychol., 1965, 2, 884-889.

BYRNE, D., YOUNG, R. K., \& GRIFFITT, W. The reinforcement properties of attitude statements. J. exp. res. Pers., 1966, 1, 266-276.

LOTT, A. J., \& LOTT, B. E. A learning theory approach to interpersonal attitudes. In T. C. Brock, A. G. Greenwald, \& T. M. Ostrom (Eds.), Attitude change theory and research. New York: Academic Press, in press.

NOTE

1. This research was supported in part by a grant, from the University Research Council of the University of Hawaii. 